\title{
CHEST LEADS IN CONGENITAL AND ACQUIRED DEXTROCARDIA
}

\author{
BY \\ J. S. RICHARDSON \\ Received February 20, 1942
}

Four cases with hearts situated in the right side of the thorax have been seen recently in a military hospital. Two of these had true dextrocardia (Cases 1 and 2), and were admitted for diseases that did not affect the heart. One was suffering from an apical lobar pneumonia and the other from a gastric ulcer, and in each the dextrocardia was an incidental finding. There was transposition of the viscera in both, and the heart was a mirror image of the normal, as shown by screening and by X-ray films in the antero-posterior and oblique positions.

The third (Case 3) had a traction dextrocardia with cardiac dullness to the right of the mid-line. X-ray examination showed that the heart was pulled over, with the apex under the right border of the sternum, and the chambers were in their normal relationship.

The fourth (Case 4) was one of eventration of the left lobe of the diaphragm of such degree that the heart was displaced to the right of the mid-line. It was not rotated from its normal relationship to the chest wall as shown by radiography and screening, and had a perfectly normal outline.

Electrocardiograms were taken and the standard leads I, II, and III were used with the chest leads $\mathrm{C}_{2} \mathrm{~F}$ and $\mathrm{C}_{4} \mathrm{~F}$, as laid down by the American Heart Association and the Cardiac Society of Great Britain and Ireland (1938). Two further chest leads were taken to reproduce, for the cases of true dextrocardia, the same arrangements of leads as is used with $\mathrm{C}_{2} \mathrm{~F}$ and $\mathrm{C}_{4} \mathrm{~F}$ in the normal subject: an upward deflection indicated a positive electrical potential in the heart. The lead that was equivalent to $\mathrm{C}_{2} \mathrm{~F}$ was taken from the right sternal margin in the fourth interspace, with the indifferent electrode on the right ankle, $\mathrm{C}_{2} \mathrm{~F}$ (right): the lead equivalent to $\mathrm{C}_{4} \mathrm{~F}$ was taken from the right mid-clavicular line in the fifth right interspace with the indifferent electrode on the right ankle, $\mathrm{C}_{4} \mathrm{~F}$ (right).

In Cases 1 and 2, the three standard leads were similar to those usually found in dextrocardia: all the waves in lead I were inverted and the maximum deflections were found in lead III instead of in lead II. The chest leads, $\mathrm{C}_{2} \mathrm{~F}$ and $\mathrm{C}_{4} \mathrm{~F}$, showed inverted $\mathrm{P}$ and $\mathrm{T}$ waves. The direction of the deflection of the $\mathbf{P}$ wave is so inconstant in chest leads if the indifferent electrode is not 
on the right arm (Deeds' and Barnes, 1940), that it must be neglected in the present instance. The inverted $T$ wave, on the other hand, is a significant feature. When the leads $\mathrm{C}_{2} \mathrm{~F}$ (right) and $\mathrm{C}_{4} \mathrm{~F}$ (right), equivalent to the chest leads $\mathrm{C}_{2} \mathrm{~F}$ and $\mathrm{C}_{4} \mathrm{~F}$ in those with normally placed hearts, were taken, the tracing was normal in all respects, and the $\mathrm{T}$ waves were positive or diphasic (Case 1, $\mathrm{C}_{2} \mathrm{~F}$ (right); see Fig. 1). These findings resemble those of Kossman (1940) who

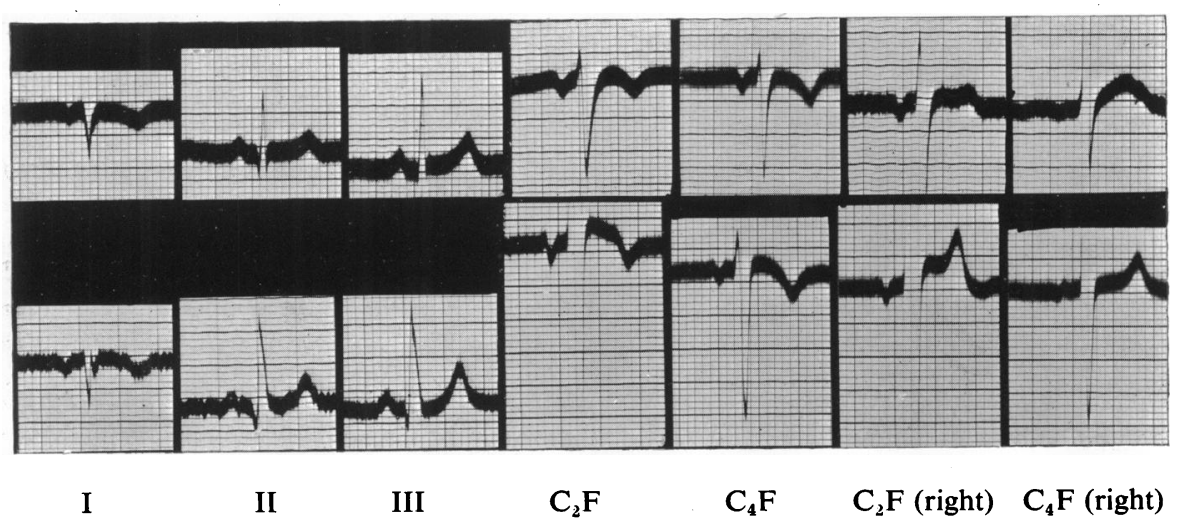

FIG. 1.-Standard and chest leads in two cases of congenital dextrocardia: Case 1 (above) and Case 2 (below). The leads are indicated below.

writes of five cases of true dextrocardia that " the $T$ wave was isoelectric or negative in leads from the left side or middle of the chest and positive in leads from the right side."

The case with a traction dextrocardia (Case 3) had normal leads I, II, III, $\mathrm{C}_{2} \mathrm{~F}$, and $\mathrm{C}_{4} \mathrm{~F}$, but $\mathrm{C}_{2} \mathrm{~F}$ (right) and $\mathrm{C}_{4} \mathrm{~F}$ (right) had upright $\mathrm{T}$ waves. Case 4 had normal leads I, II, III, $\mathrm{C}_{2} \mathrm{~F}$, and $\mathrm{C}_{4} \mathrm{~F}$, and a negative $\mathrm{T}$ wave in $\mathrm{C}_{4} \mathrm{~F}$ (right), but a positive $T$ was present in $\mathrm{C}_{2} \mathrm{~F}$ (right) (see Fig. 2).

It was decided to find out if normally placed hearts would give a downward deflection of $\mathrm{T}$ in leads $\mathrm{C}_{2} \mathrm{~F}$ (right) and $\mathrm{C}_{4} \mathrm{~F}$ (right). Cases were therefore

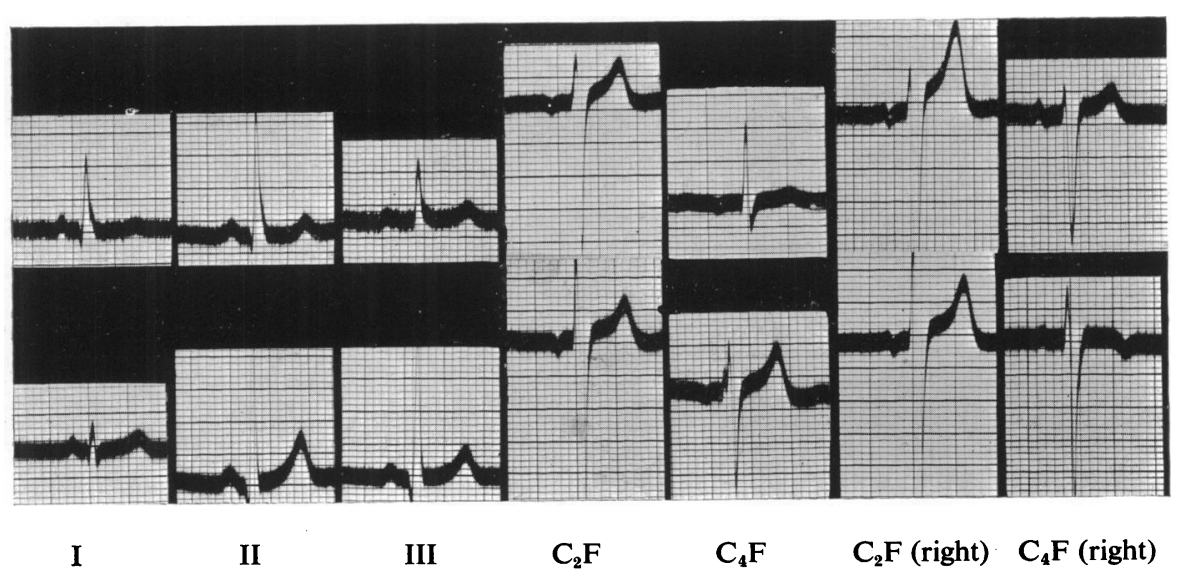

FIG. 2.-Standard and chest leads in two cases of acquired dextrocardia: Case 3 (above) and Case 4 (below). The leads are indicated below. 
selected who gave no past history of rheumatism or of any other condition that might have damaged the heart, had no symptoms found in cardiac disease, had a good exercise tolerance, and hearts that were normal, clinically and radiologically. Eighteen cases were examined and gave normal tracings in the standard leads. The results in regard to the direction of the $T$ waves were as follows:

\begin{tabular}{|c|c|c|c|c|c|}
\hline & & & Positive & Negative & Varying * \\
\hline $\mathrm{C}_{4} \mathrm{~F}$ & $\cdots$ & .. & 18 & 0 & 0 \\
\hline $\mathrm{C}_{2} \mathrm{~F}$ & $\ldots$ & .. & 15 & 1 & 2 \\
\hline $\mathrm{C}_{2} \mathrm{~F}$ (right) & $\ldots$ & $\ldots$ & 1 & 14 & 3 \\
\hline $\mathrm{C}_{4} \mathrm{~F}$ (right) & $\ldots$ & $\ldots$ & 0 & 18 & 0 \\
\hline
\end{tabular}

* In these cases the $T$ wave varied from tracing to tracing between positive diphasic and negative deflections.

Thus in the normal, $\mathrm{C}_{4} \mathrm{~F}$ always had a positive, and $\mathrm{C}_{4} \mathrm{~F}$ (right) a negative $\mathrm{T}$ wave, while the sternal leads were predominantly positive when taken on the left, and negative on the right. Deeds and Barnes (1940) found positive $T$ waves in leads $\mathrm{C}_{2} \mathrm{~F}$ and $\mathrm{C}_{4} \mathrm{~F}$ in 99 and 100 tracings respectively from their 100 normal cases. They also found that $\mathrm{T}$ was negative or diphasic in 79 per cent of cases in lead $\mathrm{C}_{1} \mathrm{~F}$, that is, with the chest electrode to the right of the sternum.

The two cases of dextrocardia had reversed deflections of the $T$ wave in the chest leads as compared with the normal.

The case of traction dextrocardia showed a mixture: the direction of the $T$ wave in leads $\mathrm{C}_{2} \mathrm{~F}$ and $\mathrm{C}_{4} \mathrm{~F}$ was positive, i.e. normal, but in the leads from the right side of the chest wall and the right ankle the direction of the $\mathrm{T}$ waves was also positive, thus resembling true dextrocardia.

Case 4 with a positive $T$ in lead $C_{2} F$ (right) but normal deflections in the other leads cannot be regarded as having an abnormal tracing, since the $\mathrm{T}$ wave in $\mathrm{C}_{2} \mathrm{~F}$ (right) was positive in one and variable in three of our eighteen normal cases and was positive in 21 per cent of Deeds and Barnes' cases.

\section{SUMMARY}

1. Two cases of congenital dextrocardia with transposition of the viscera were found to have in chest leads $T$ waves that had deflections in the opposite direction to the normal.

2. In two cases of acquired dextrocardia, one had $\mathrm{T}$ waves in leads, taken from the right side of the chest, that resembled those of congenital dextrocardia in direction, but the other conformed to the tracing found in about 20 per cent of subjects with normally placed hearts.

It is a pleasure to express my thanks to Professor W. T. Ritchie for his interest and advice, to Professor D. M. Dunlop, Director of the Clinical Laboratory, Edinburgh Royal Infirmary, for his kindness in permitting me to use the Electrocardiographic Department, and to Mr. R. P. Danskin for taking the tracings and for his generous help.

My thanks are also due to Lt.-Col. J. G. Ronaldson, R.A.M.C., for permission to forward this paper for publication.

\section{REFERENCES}

Deeds, D., and Barnes, A. R. (1940). Ibid., 20, 261.

Kossman, C. E. (1940). Ibid., 20, 322.

Standardization of præcordial leads (1938). Amer. Heart J., 15, 107, 235. 